\title{
El Régimen Jurídico del municipio turístico en Andalucía. El Derecho a la carta
}

\author{
Severiano Fernández Ramos \\ Profesor Titular de Derecho Administrativo \\ Universidad de Cádiz
}

Ponencia presentada en las VI Jornadas de Derecho Turístico: El Municipio Turístico, organizadas por la Asociación Andaluza de Derecho Turístico, Málaga, octubre de 2003.

SUMARIO: I. INTRODUCCIÓN. 1.1. El fenómeno de los Municipios turísticos. 1.2. La recepción del MT en la legislación estatal y autonómica. II. CONCEPTO DE MUNICIPIO TURÍSTICO. III. REQUISITOS PREVIOS PARA LA DECLARACIÓN DE MT. IV. ELEMENTOS DE VALORACIÓN PARA LA DECLARACIÓN DE MT. 4.1. Los criterios en general. 4.2. Esfuerzo presupuestario en la prestación de servicios municipales. 4.3. Planeamiento urbanístico general. 4.4. Planeamiento turístico. 4.5. Espacios Naturales Protegidos. V. PROCEDIMIENTO PARA LA DECLARACIÓN DE MT. 5.1. Inicio del procedimiento. 5.2. Instrucción del procedimiento. 5.3. Resolución del procedimiento. 5.4. Efectos de la declaración de MT. VI. CONVENIOS INTERADMINISTRATIVOS. 6.1. Organización de los Convenios. 6.2. Fines de los Convenios. 6.3. Contenido de los convenios. 6.4. Obligaciones de los municipios. 6.5. Obligaciones de la Administración de la Junta de Andalucía. VII. PÉRDIDA DE LA CONDICIÓN DE MUNICIPIO TURÍSTICO. VIII. CONCLUSIÓN.

\section{INTRODUCCIÓN}

\section{El fenómeno de los Municipios turísticos.}

Los Municipios con gran afluencia estacional de turistas presentan problemas específicos derivados del hecho de que esta población no residente demanda una serie de servicios comunes a los precisados por la población residente -higiene, saneamiento, limpieza de playas, seguridad...-, así como otros servicios específicos -información turística, oferta cultural y de ocio...-, y que, además, deben ser prestados en condiciones de calidad, puesto que és- 
ta es una de las claves para ofrecer un producto turístico competitivo en el mercado internacional. Ahora bien, dado que el actual modelo de financiación municipal tiene como principal factor determinante el de la población de derecho, esta otra población turística o de hecho, aun cuando pueda suponer la multiplicación de la población residente, no es tenida en cuenta a la hora de asignar las transferencias anuales del Estado a los municipios. Esta circunstancia sitúa a los Ayuntamientos ante una difícil tesitura, pues o se ven obligados a incrementar la presión fiscal que deben soportar los ciudadanos residentes, o bien se plantea la degradación del entorno con la excusa de que la especulación urbanística es imprescindible para nivelar los servicios ${ }^{1}$.

Por estas razones desde, al menos, mediados de la década de los ochenta, se viene planteando la necesidad de que el ordenamiento español de carta de naturaleza legal a los municipios turísticos, y afronte los problemas específicos que plantean, entendiendo básicamente por tales a aquellos municipios que experimentan una afluencia de turistas en grado tal que afecta sensiblemente a la viabilidad de los servicios municipales ${ }^{2}$.

\subsection{La recepción del MT en la legislación estatal y autonómica.}

Ahora bien, si los Municipios con gran afluencia estacional de turistas constituyen una realidad social que no se puede desconocer, darle carta de naturaleza legal ha sido y es aún un paso difícil. Inicialmente, la acogida legal del Municipio Turístico (en adelante MT) surge a partir de la mención del art. 30 de la Ley Básica de Régimen Local de 1985 de la posibilidad de que las Leyes sobre régimen local de las Comunidades Autónomas puedan establecer regímenes especiales para determinadas categorías de Municipios (de carácter rural, histórico-artístico...), entre las que menciona expresamente a "aquellos que tengan predominio en su término de actividades turísticas" 3 .

\footnotetext{
${ }^{1}$ J. L. RIVERO YSERN, "Notas sobre la Ley 12/1999, de 15 de diciembre, reguladora del Turismo en Andalucía”, Documentación Administrativa, no 259-260, 2001, p. 202. Del mismo autor, "Notas sobre el municipio turístico en la Ley 12/99 del Turismo de Andalucía", en "Decreto y Turismo” III, Jornadas de Decreto Turístico, Junta de Andalucía, Sevilla, 2000, pp. 85 y ss.

${ }^{2}$ Vid. el pionero trabajo de Luis CORNO CAPARRÓS, "El estatuto legal del Municipio Turístico: apuntes para una propuesta", Rev. Española de Derecho Administrativo, nº 42, 1984, pp. 423 y ss.

${ }^{3}$ Vid. M. J. SARMIENTO ACOSTA, "El régimen especial del Municipio Turístico", Actualidad Administrativa, no . 45, 1994, pp. 668 y ss.; J. SUAY RINCÓN-M. DEL PINO RODRÍGUEZ GONZALÉZ, "Las competencias turísticas de los Municipios. En particular, la categoría de los Municipios turísticos", I Congreso Universidad y empresa, Tirant lo Blanch, Valencia, 1999, pp. 70 y ss.
} 
Sin embargo, la recepción del MT en la legislación autonómica ha sido muy irregular, hecho motivado, tal vez, por las expectativas que esta figura puede generar, pues es evidente que la incorporación de esta figura es vista, desde la perspectiva local, como la panacea de los muchos y seculares problemas locales, pasando a formar parte prestamente parte de los programas y propuestas electorales de las distintas fuerzas políticas locales. A este recelo autonómico frente a la dinámica que pueda generar el MT en el ámbito local, deben añadirse las propias responsabilidades que ciertamente incumben al Estado ante este fenómeno, desde el punto de vista de la ordenación de las finanzas de las entidades locales ${ }^{4}$.

Lo cierto es que, desde la pionera ordenación contenida en la Ley Municipal y de Régimen Local de Cataluña de 1987 hasta la fecha, sólo ocho Comunidades Autónomas han contemplado en sus Leyes la figura del MT. De ellas, dos Comunidades Autónomas (Cataluña y Galicia) ordenan la figura tanto en la Ley de Régimen Local como en la Ley de Turismo ${ }^{5}$, una Comunidad Autónoma (la de Madrid) contempla la figura exclusivamente en la Ley de Régimen Local ${ }^{6}$, y las cinco restantes (Murcia, Comunidad Valenciana, Cantabria, Andalucía y Aragón) contienen la figura del MT exclusivamente en su respectiva Ley de Turismo?.

Por el contrario, no recogen la figura del MT, ni en sus leyes de régimen local o de turismo, las nueve Comunidades Autónomas siguientes: País Vasco,

\footnotetext{
${ }^{4}$ Como ya señalara L. CORNO CAPARRÓS, "El estatuto legal del Municipio Turístico: apuntes para una propuesta", op. cit., p. 428, sólo el Estado puede modificar el régimen de las haciendas locales en lo concerniente a la participación municipal en los tributos del Estado.

${ }^{5}$ En el caso de Galicia, la Ley 5/1997, de 22 de julio, de Administración Local -art. 90- y la Ley 9/1997 de Turismo son prácticamente contemporáneas, lo que ha facilitado su práctica concordancia. En cambio, en el caso de Cataluña, la Ley Municipal y de Régimen Local de Cataluña de 1987 y la Ley de Turismo 13/2002 distan quince años entre sí, lo que explica que existan importantes diferencias entre ambas.

${ }^{6}$ Ley de la Comunidad de Madrid 2/2003, de 11 de marzo, de Administración Local -art. 41-, entre los regímenes municipales especiales.

${ }^{7}$ Ley de la Región de Murcia 11/1997 -art. 51-, Ley de la Comunidad Valenciana 3/1998 -arts. 25 a 31, Ley de Cantabria 5/1999 -art. 39.2-, Ley de Andalucía 12/1999 -arts. 6 a 8-, Ley de Cataluña 13/2002 -arts. 18 a 22-, Ley de Aragón 6/2003 -art. 15-.
} 
Canarias $^{8}$, Castilla y León ${ }^{9}$, Extremadura, Islas Baleares, Castilla-La Mancha, La Rioja, Asturias y Navarra. Ciertamente, en algún caso -como tal vez el de las Comunidad Autónoma insulares-, la mayoría de los Municipios podrían alcanzar tal distinción, lo cual se compadece mal con su carácter de régimen especial, y en otros casos de Comunidades uniprovinciales, la situación podría ser la extrema opuesta, es decir, sólo podrían alcanzar la calificación contados municipios, de tal modo que podría ser excesivo forzar una regulación abstracta para realidades muy singulares, que podrían ordenarse de un modo más directo mediante soluciones "ad hoc". Pero no es menos cierto que en otros casos ha podido pesar en esta inhibición el temor antes indicado a las expectativas que suscita la creación de esta figura.

Pero este recelo a la plasmación legal del MT está también presente en aquellas Comunidades Autónomas que han dado el paso de contemplar la figura, y que comúnmente no establecen un sistema reglado para acceder a la calificación de MT, reservando a la Administración autonómica importantes márgenes de valoración -para la declaración de MT "se tendrán en cuenta" los elementos siguientes, enumerando la norma una serie de exigencias de contenido eminentemente abierto $^{10}$ - . Asimismo, este recelo se manifiesta también en la vaguedad e indefinición en la que quedan los efectos de la declaración de MT: incluso se especifican las obligaciones que supone para el municipio su declaración de turístico, pero se deja en la más absoluta ambigüedad los beneficios que reporta ${ }^{11}$. Por último, este recelo está presente en algunas exclusiones: como la establecida en la Ley de Andalucía 12/1999 -disposición adicional 1ª-, en virtud de la cual se excluyen de la declaración de MT a las ciudades de más de cien mil habitantes, que se remiten a un Programa de Grandes Ciudades del Plan General de Turismo, exclusión que únicamente se explica en razones pragmáticas*.

\footnotetext{
${ }^{8}$ Y ello a pesar de la Ley de Régimen Jurídico de las Administraciones Públicas de Canarias 14/1990 había previsto - disposición adicional $4^{a}$ - la ordenación del estatuto de los Municipios turísticos.

${ }^{9}$ La Ley de Castilla León 1/1998, de 4 de junio, de Régimen Local, se limita a contener una referencia vaga a aquellos municipios que cuenten con servicios culturales, educativos, sanitarios, sociales, administrativos o de otra naturaleza mediante los cuales se satisfaga la demanda "de los residentes en otros municipios limítrofes" -art. 79-, y que, por tanto, parece pensar en el fenómeno metropolitano, de modo que no se corresponde con la noción asumida de MT.

${ }^{10}$ Ley de Aragón 6/2003 -art. 15.2-.

${ }^{11}$ Ley Cataluña 13/2002 -art. 19-.

* El Plan General de Turismo, aprobado por Decreto 340/2003, de 9 de diciembre, comtempla el Programa de grandes ciudades en el marco de la estrategia de ordenación de los recursos y reequilibrio del espacio turístico.
} 
Y, en cualquier caso, las Leyes que contemplan la figura del MT remiten su operatividad a un posterior desarrollo reglamentario, y ciertamente es en este ámbito reglamentario donde se perfila la figura y se determinan sus aspectos esenciales, tales como los requisitos, su cuantificación y acreditación, así como el procedimiento a seguir. Pues bien, de las ocho Comunidades Autónomas que a nivel de Ley contemplan la figura sólo tres han dictado los reglamentos del desarrollo de la misma: Galicia ${ }^{12}$, Comunidad Valenciana ${ }^{13}$ y Andalucía ${ }^{14}$. En el algunos casos, como las Comunidades de Aragón y Madrid, puede estar justificada esa ausencia de desarrollo reglamentario debido a su reciente consagración legal, pero en otros casos no cabe tal excusa. Y aquí el ejemplo más clamoroso es el de Cataluña que fue pionera al introducir esta figura hace ya nada menos que dieciséis años.

Finalmente, si descendemos al ámbito de aplicación efectiva de la figura del MT, hasta hace bien poco sólo dos Comunidades Autónomas (Galicia y Comunidad Valenciana) habían aplicado la figura legal, procediendo a la declaración de diversos municipios turísticos en sus respectivos territorios. Y, tras el reciente acuerdo del Consejo de Gobierno, de 21 de octubre de 2003, de declaración de MT de Benalmádena, Andalucía se ha sumado a este reducido grupo de Comunidades Autónomas con experiencia efectiva en esta materia $^{15}$.

\section{CONCEPTO DE MUNICIPIO TURÍSTICO}

Tradicionalmente, ha existido un cierto consenso en situar la noción de MT en el fenómeno de desproporción relevante entre población residente y población turística, y los problemas que ello comporta para el municipio. Este es el concepto que se plasmó en la primera norma que ordenó la figura del MT, la Ley de Cataluña 8/1987 Municipal y de Régimen Local, al declarar que

\footnotetext{
12 Decreto 39/2001, de 1 de febrero, por el que se refunde la normativa en materia de Consejo Gallego de Turismo, declaraciones de municipio turístico gallego y de fiestas de Galicia de interés turístico.

${ }^{13}$ Decreto 71/2000, de 22 de mayo, por el que se aprueba el Reglamento regulador de los Convenios previstos en la Ley 3/1998 en relación con el Municipio Turístico.

${ }^{14}$ Decreto 158/2002, de 28 de mayo, de Municipio Turístico.

${ }^{15}$ Acuerdo del Consejo de Gobierno de 21 de 0ctubre de 2003, BOJA núm. 213, de 5.11.2003.
} 
tendrán la consideración de municipios turísticos "aquellos en los que, por afluencia estacional, la media ponderada anual de población turística sea superior al número de residentes, y el número de alojamientos turísticos superior al número de viviendas de residencia primaria" -art. 72.1-. Asimismo, este concepto luce en la Ley de la Comunidad de Madrid 2/2003 de Administración Local -art. 41.1-, al definir a los Municipios turísticos como aquellos "que soportan, temporal o estacionalmente, un considerable aumento de su población o reciben un flujo de visitantes que afecta a la viabilidad de los servicios municipales habituales". De este modo, la noción de MT ha sido diferente a la Municipio o zona de "interés turístico", esto es una zona con recursos y atractivos turísticos relevantes, figura ésta que en nuestro ordenamiento se ordena ya en la Ley 197/1963, de 28 de diciembre, de centros y zonas de interés turístico nacional.

Sin embargo, esta noción inicial adoptada desde la legislación de régimen local se ha desdibujado, al menos en parte, en la legislación turística. En efecto, aunque sigue primando la noción de MT como municipio de gran afluencia turística, con independencia de la importancia de sus recursos turísticos, se observa una tendencia en la legislación turística a introducir en la noción misma de MT o, al menos, en el proceso de valoración para la obtención de esta calificación, de elementos propios de lo que sería más bien un municipio de interés turístico: así la Ley de la Región de Murcia 11/1997 -art. 51.3- se refiere a la existencia de una "oferta turística local" que pueda justificar la calificación, o la Ley de Aragón 6/2003 -art. 15.2- se refiere a la "relevancia de los recursos turísticos existentes" en el término municipal. Pero el caso más radical es el de la Ley de Cataluña 13/2002, la cual separándose del criterio antes señalado de la Ley 8/1987 Municipal y de Régimen Local, establece dos nociones diversas de MT: la tradicional 'basada en' la afluencia de turistas- y una nueva: simplemente que el término municipal incluya un "recurso turístico esencial”, en el sentido de la Ley 13/2002 -arts. 18.1 y 5 - $^{16}$, esto es un recurso con capacidad para generar las corrientes de turismo más relevantes de la Comunidad. De este modo, se relativiza la tradicional distinción entre MT y Municipio de interés turístico.

De otro lado, en algunas Comunidades Autónomas se prevé la extensión de la categoría de MT a otros ámbitos infra y supramunicipales. Así, en Can-

\footnotetext{
${ }^{16}$ De hecho, la propia Ley de Cataluña 13/2002 -art. 23.1- declara que tienen la consideración de "municipio de interés turístico" los municipios dentro de cuyo término municipal se halle ubicado un recurso turístico esencial.
} 
tabria se prevé la figura de las Comarcas Turísticas, que agruparán territorios identificados por la unidad de su recurso turístico, y que, por tanto, se sitúa de lleno en la noción tradicional de zonas de interés turístico ${ }^{17}$. Y, por su parte, en Aragón se contempla la declaración de "pueblos turísticos" a entidades locales menores que reúnan los requisitos establecidos para los $\mathrm{MT}^{18}$.

En el caso de Andalucía, como el de Galicia o el de la Comunidad Valenciana, aún se mantiene en sus líneas fundamentales la conceptuación tradicional de MT, con alguna matización que se señalará más adelante ${ }^{19}$.

\section{REQUISITOS PREVIOS PARA LA DECLARACIÓN DE MT}

Si inicialmente, como se ha dicho, la figura del MT se identifica con una relevante desproporción entre población de derecho y población turística, es necesario definir y cuantificar la noción de "población turística" a estos efectos, así como establecer unos parámetros, necesariamente convencionales, pero que determinen con seguridad jurídica en qué caso un municipio cuenta con una población turística relevante para ser calificado o, al menos, optar a la calificación de MT.

En general, la noción de "población turística", en oposición a la población que ostenta la condición legal de vecinos del Municipio, se desglosa en tres tipos de destinos turísticos: primero, población que se aloja en algún establecimiento turístico en sentido propio ubicado en el Municipio; segundo, población que visita algún recurso turístico del Municipio pero sin alojarse en el mismo; y, tercero, población que se aloja temporalmente en el Municipio, por razones distintas a las laborales, en una vivienda que no tiene la condición de alojamiento turístico -típicamente su segunda residencia-.

\footnotetext{
${ }^{17}$ Ley de Cantabria 5/1999 -art. 39.1-.

${ }^{18}$ Ley de Aragón 6/2003 -art. 15.6-.

${ }^{19}$ Sobre la Ley 12/1999 de Turismo de Andalucía, véanse los siguientes estudios publicados en la Rev. Andaluza de Administración Pública, número extraordinario 2/2003, volumen 2, pp. 115 y ss.: E. ROCA ROCA, "El turismo y el Estatuto de Autonomía de Andalucía"; R. RODRÍGUEZ DE LEÓN, "Una aproximación a la Ley de Turismo de Andalucía"; F. VILLALVA PÉREZ, "Aspectos constitucionales, legales y organizativos del Turismo en Andalucía"; R. Mª ILDEFONSO HUERTAS, "Las políticas de turismo en la Comunidad Autónoma de Andalucía".
} 
Ahora bien, si los tres tipos de población turística están bien definidos, el peso que han de tener cada uno de ellos, aisladamente o combinados, así como su cuantificación respectiva para la declaración de MT, es una cuestión que ha recibido un tratamiento dispar en las normas autonómicas. Así, p. j., en unos casos la cuantificación de la población de hecho está referida exclusivamente a "las temporadas turísticas" ${ }^{20}$, mientras que en otros casos se opta por ponderar la población turística en el cómputo anual ${ }^{21}$.

En Andalucía, la Ley 12/1999 dispuso -art. 6.1- que se consideran Municipios Turísticos, "aquéllos que cumplan los criterios que reglamentariamente se establezcan y entre los cuales deberán figurar la población turística asistida, el número de visitantes y la oferta turística”. Además, la Ley 12/1999 explicitó -art. 6.3- que se considera población turística asistida "la constituida por quienes no ostenten la condición de vecinos del municipio ${ }^{22}$ pero tengan estancia temporal en el mismo por razones de visita turística, segunda residencia o alojamiento turístico. Su determinación se efectuará por los medios de prueba que reglamentariamente se establezcan"23.

De este modo, la Ley 12/1999, a diferencia de otras Leyes autonómicas, remitió a la potestad reglamentaria la práctica configuración de los requisitos y, con ellos, de la noción misma de MT. A este respecto, el Decreto 158/2002, partiendo de los tres tipos de estancia temporal que menciona la Ley (visita, segunda residencia y alojamiento turístico), y siguiendo los criterios de la Ley de Galicia 9/1997 de Turismo -art. 8-, diferencia tres tipos de destinos turís-

${ }^{20}$ Ley de Aragón 6/2003 -art. 15.1-, la cual exige que se trate de municipios cuya población de hecho al menos duplique la población de derecho en las temporadas turísticas.

${ }^{21}$ Leyes de Galicia 9/1997 de Turismo -art. 8- y 5/1997 de Administración Local de Galicia -art.- 90-, que se refieren a los municipios en los que, debido a la afluencia periódica o estacional, la media ponderada anual de población turística sea superior al $25 \%$ del número de residentes

${ }^{22}$ Como es sabido, son vecinos del municipio las personas que residiendo habitualmente en el mismo, se encuentren inscritos en el Padrón municipal de habitantes -art. 55.1 del Real Decreto 1690/1986, de 11 de julio, de Población y Demarcación Territorial, modificado por Real Decreto 2612/1996, de 20 de diciembre.

${ }^{23}$ En la noción de población turística asistida de la Ley 12/1999 puede observarse alguna incoherencia, pues, de un lado, el art. 6.1 se refiere al número de visitantes como un criterio diverso al de población turística asistida; pero, sin embargo, el art. 6.3 incluye dentro de la noción misma de población turística asistida a aquellos que realizan una estancia por razones de "visita turística”. 
ticos para acceder a la declaración de MT: primero, en orden al número de pernoctaciones en alojamientos turísticos; segundo, según el número de viviendas de segunda residencia; $y$, en tercer lugar, en orden al número de visitantes, requiriendo en cada caso unos mínimos en relación con los datos de la población de derecho del Municipio. Ahora bien, curiosamente, el Decreto 158/2002 obvia, a estos efectos, la noción de población turística asistida acuñada por la Ley 12/1999, fijando directamente los módulos para cada tipo de destino turístico, añadiendo además una cuarta posibilidad de combinación de dos tipos de destinos turísticos.

Por último, debe observarse que el Decreto 158/2002 no ha otorgado relevancia alguna a la posible declaración previa por la propia Administración autonómica (a través de la Consejería competente en materia de comercio) del término municipal como zona de gran afluencia turística, a efectos de horarios comerciales, de acuerdo con la Ley de Comercio Interior de Andalucía -art. 20.2-, la cual considera zonas de gran afluencia turística los términos municipales o parte de los mismos en los que, en determinados períodos del año, la media ponderada anual de población sea significativamente superior al número de residentes o en los que tenga lugar una gran afluencia de visitantes por motivos turísticos. Es decir, una noción muy próxima a la de MT. Con todo, debería entenderse que la existencia previa de dicha declaración zona de gran afluencia turistica constituye un elemento que deberá, al menos, valorar la Administración autonómica ${ }^{24}$.

En concreto, las posibles vías contempladas en el Decreto 158/2002 para solicitar la declaración de MT serían las cuatro siguientes:

a). "Que el número de pernoctaciones diarias en media anual (pernoctaciones/365) en los establecimientos de alojamiento turístico, sea superior al $10 \%$ de vecinos del municipio, o que se alcance este porcentaje durante al menos tres meses al año, computándose para ello la media diaria mensual (pernoctaciones de cada mes/30)". El propio Decreto 158/2002 precisa que, a estos efectos, se entiende por "establecimiento de alojamiento turístico" cualquiera de las categorías contempladas en el art. 36.1 de la Ley 12/1999, de 15 de diciembre, del Turismo, incluidos, por tanto, no sólo los establecimientos hoteleros sino también los extrahoteleros, como los apartamentos turísticos, inmuebles de uso turístico en régimen de aprovechamiento por turno, las ca-

\footnotetext{
${ }^{24}$ En el caso del MT de Benalmádena, se aportó dicha declaración.
} 
sas rurales y los campamentos de turismo ${ }^{25}$. En cambio, no se incluirían en este apartado las pernoctaciones que tengan lugar en las llamadas viviendas turísticas, tanto vacacionales como de alojamiento rural. Además, debe entenderse que únicamente pueden computarse a estos efectos las pernoctaciones en establecimientos de alojamiento turístico regulares o legalizados, esto es los que cuentan la preceptiva licencia municipal de apertura ${ }^{26}$ y están inscritos en el Registro de Turismo de Andalucía -arts. 34.1 y 35.1 Ley 12/1999-, lo cual puede suponer un serio obstáculo en el ámbito rural, dado que la gran mayoría de las casas rurales en funcionamiento no están registradas oficialmente ${ }^{27}$. Asimismo, el Decreto 158/2002 precisa que el cómputo del número de pernoctaciones en los establecimientos de alojamiento turístico será de acuerdo con los datos oficiales elaborados por la Consejería de Turismo y Deporte. De este modo, se trata de datos que constan en los registros de la propia Consejería, por lo que no deben ser aportados por los Municipios. Más aún, debe entenderse que los Municipios interesados en la calificación de MT están legitimados para acceder previamente a dicha información. De otro lado, las cifras de vecinos a tener en cuenta son las del padrón municipal declaradas oficiales en el momento de la solicitud ${ }^{28}$. Como es sabido, corresponde al Gobierno de la Nación aprobar anualmente, mediante Real Decreto, las cifras oficiales de población de los municipios españoles ${ }^{29}$. Finalmente, debe señalarse que el Decreto 158/2002, a diferencia de otras normas autonómicas, no utiliza como criterio la oferta turística del municipio, y ello a pesar de que la propia Ley 12/1999 -art. 6.1- dispuso -como antes se indicó- que se consideran Municipios Turísticos, "aquéllos que cumplan los criterios que reglamentariamente se establezcan y entre los cuales deberán figurar la población turísti-

\footnotetext{
${ }^{25}$ Además, de acuerdo con el Decreto 20/2002 sobre Turismo Rural, habrá que incluir también a los complejos turísticos rurales -art. 18-.

${ }^{26}$ Así, expresamente, Decreto del Consejo de Gobierno de Galicia 39/2001 -art. 13-.

${ }^{27}$ La Administración turística reconoció en marzo del 2001 que sólo un 20\% de los establecimientos que operan en el sector estaban registrados oficialmente. El País, 11.3.2001. Y es muy posible que los cifras de "paralegalidad" sean aún más altas que las reconocidas por la Administración.

28 Debe recordarse que la Ley 4/1996, de 10 de enero, de modificación de la LBRL, eliminó la inclusión de los transeúntes en el Padrón municipal de habitantes.

${ }^{29}$ Art. 82.2 del Real Decreto 1690/1986 de Población y Demarcación Territorial.
} 
ca asistida, el número de visitantes y la oferta turística" ${ }^{30}$. No obstante, debe reconocerse que el criterio adoptado por el Decreto 158/2002 refleja con mayor fidelidad el grado de afluencia turística real al Municipio ${ }^{31}$.

b). "Que el número de viviendas de segunda residencia supere al de viviendas principales del municipio, siempre que éstas últimas sean más de quinientas". En este cómputo habrá que incluir las llamadas viviendas turísticas, tanto vacacionales como de alojamiento rural, y que fueron descartadas del apartado anterior, por no tratarse oficialmente de establecimientos de alojamiento turístico. Asimismo, la imposición de un número mínimo de viviendas supone descartar a los pequeños núcleos residenciales. En todo caso, debe observarse que el criterio adoptado en este punto por el Decreto 158/2002 es muy estricto, si se compara con el establecido en el Decreto de Galicia 39/2001 -art. 9-, el cual únicamente exige el número de alojamientos turísticos y de segundas residencias (sumados ambos) sea superior al $50 \%$ del número de viviendas de residencia primaria ${ }^{32}$. En cambio, este criterio de la norma andaluza ha sido adoptado por la posterior Ley de Aragón 6/2003 -art. 15.1-. Por lo demás, el propio Decreto 158/2002 precisa que el cómputo del número de viviendas de segunda residencia se realizará de acuerdo con los datos oficiales del último Censo de Edificios y Viviendas ${ }^{33}$. Se tratan, por tanto, de datos públicos de fácil aportación.

\footnotetext{
30 Así, las Leyes de Galicia 9/1997 de Turismo -art. 8- y 5/1997 de Administración Local de Galicia -art.- 90-, admiten de un modo alternativo el criterio de la afluencia de población turística y el número de alojamientos turísticos (superior al $50 \%$ del número de viviendas de residencia primaria). Y, de modo similar, la Ley de Aragón 6/2003 -art. 15.1- refiere que se trate de poblaciones en las que el número de plazas turísticas hoteleras y extrahoteleras duplique, al menos, la población de derecho.

${ }^{31}$ En el caso del MT de Benalmádena se aportó también la cifra del número total de camas regladas en el municipio.

32 Por su parte, la Ley de Cataluña 13/2002 -art. 18.1- exige que el número de plazas de alojamiento turístico "y" de plazas de segunda residencia sea superior al número de vecinos, de tal modo que se suman las plazas de establecimientos turísticos y de segundas residencias.

${ }^{33}$ Como es sabido, el Real Decreto 691/1990, de 18 de mayo, por el que se dispone la formación de los censos de edificios y locales, atribuye al Instituto Nacional de Estadística la formación del censo.

${ }^{34}$ Este requisito coincide con el establecido en el Decreto de Galicia 39/2001 -arts. 9 y 13-.
} 
c). "Que el número de visitantes sea al menos cinco veces superior al de vecinos, repartidos los primeros en al menos más de treinta días al año" ${ }^{4}$. De este modo, no basta un acontecimiento puntual -como una feria, fiesta o certamen-, si bien la exigencia puede cumplirse de modo tanto concentrado -p. j., durante las vacaciones estivales-, como repartido en fiestas y fines de semana -caso del turismo de nieve-. Asimismo, el Decreto 158/2002 precisa que, a estos efectos, se considera "visitante" a la persona que se desplaza a un lugar distinto al de su entorno habitual sin alojarse en ningún establecimiento turístico, no siendo el motivo principal del viaje el ejercicio de una actividad remunerada en el lugar visitado. Además, establece que el número de visitantes diarios se computará "mediante el conteo de las visitas diarias en el recurso turístico de mayor afluencia del municipio". Y estos datos se acreditarán mediante "certificado" en el que conste las visitas realizadas al recurso turístico más visitado, expedido por el titular o gestor del mismo, de acuerdo con el sistema de conteo establecido -art. 5.2 Decreto 158/2002_ ${ }^{35}$. Ahora bien, si el recurso turístico no es de titularidad municipal, los datos requeridos no serán detentados por el Municipio, y si, además, el recurso es de titularidad privada, el Ayuntamiento no podrá exigir su expedición, por lo que precisará de la colaboración voluntaria del titular del mismo. Por lo demás, cabe plantearse la razón de la restricción del criterio a un único recurso turístico. Aquí ha podido pesar la consideración según la cual el mismo visitante acude a los principales recursos turísticos del Municipio, de tal modo que se duplicarían artificialmente las cifras de visitantes ${ }^{36}$.

d). Que el número de pernoctaciones diarias en media anual (pernoctaciones/365) en los establecimientos de alojamiento turístico sea superior al $5 \%$ por ciento de vecinos del municipio y, "acumulativamente" 37 , el número de visitantes sea al menos 2,5 veces superior al de vecinos, repartidos los primeros en al menos más de treinta días al año ${ }^{38}$.

\footnotetext{
${ }^{35}$ En puridad, no se trata de un "certificado" sino de una declaración, puesto que salvo que el recurso esté gestionado por una Administración, tal documento no está provisto de especial valor probatorio.

${ }^{36}$ En el caso del MT de Benalmádena, el Ayuntamiento presentó datos de las visitas a dos recursos turísticos: el parque de atracciones Tívoli World y el Puerto Deportivo.

${ }^{37}$ El Consejo Consultivo Andaluz, en su dictamen al Proyecto de Decreto, de 21 de marzo de 2002 señaló que debía aclararse que el cumplimiento de la mitad de los requisitos de los apartados a) y c) tenía carácter cumulativo, observación que fue recogida en el texto final de la disposición.

${ }^{38}$ Dado que el Decreto se refiere de forma genérica a "la mitad de las exigencias que se contemplan en las letras a) y c), en relación con ésta cabría plantear si se cumple la norma rebajando en lugar del número de visitantes (cinco veces el de vecinos) el número mínimo de treinta días al año: es decir, admitiendo el número de visitantes (cinco veces el de vecinos), pero repartidos quince días al año.
} 


\section{ELEMENTOS DE VALORACIÓN PARA LA DECLARACIÓN DE MT.}

\subsection{Los criterios en general.}

La Ley 12/1999 -art. 7.1- establece que para la declaración de MT se tendrán en cuenta, en especial, las actuaciones municipales en relación a:

a). Los servicios mínimos que presta el municipio respecto a los vecinos y la población turística asistida ${ }^{39}$.

b). Los servicios específicos en materia de salubridad pública e higiene en el medio urbano y natural y de protección civil y seguridad ciudadana "y cuantos sean de especial relevancia turística" ${ }^{40}$.

Por su parte, el Decreto 158/2002 -art. 3- no sólo concreta con mayor precisión este criterio, sino que añade tres elementos adicionales, no previstos en la Ley 12/1999, sin que ello suponga necesariamente una extralimitación. De entrada, debe observarse que se trata de un criterio extendido en la legislación autonómica. Así, de modo similar, las Leyes de Galicia 9/1997 -art. 8-, y de Aragón 6/2003 -art. 15.2-, tras determinar los requisitos para solicitar la declaración, añaden una serie de criterios a valorar muy similares a los previstos en el ordenamiento andaluz ${ }^{41}$.

Con carácter general, se suscita la cuestión de la relevancia de estos elementos en orden a la calificación de MT. Del conjunto de la Ley 12/1999 y del Decreto 158/2002 parece desprenderse que el cumplimiento de los llamados "requisitos previos" previstos en el art. 2 del Decreto es condición necesaria pero no suficiente para la obtención de la calificación de MT, pues además de

${ }^{39}$ El Consejo Consultivo de Andalucía llamó la atención de la indefinición de este apartado, por considerar que no se concreta si los servicios mínimos a que hace referencia son los del artículo 26 de la LBRL o si se alude a otro nivel de prestación de servicios, cuestión que resuelve el Decreto $158 / 2002$.

${ }^{40}$ El Consejo Consultivo de Andalucía señaló que este apartado no se ajusta al elenco de competencias municipales previsto en el art. 25 de la LBRL.

${ }^{41}$ Más alejados son los criterios previstos en la Ley de Cantabria 5/1999 -art. 39.2-, y, sobre todo, en la Ley de la Región de Murcia 11/1997 -art. 51.3-, referidos fundamentalmente a la oferta turística local y a su promoción. 
constarse el cumplimiento de los parámetros mínimos de población turística, la Administración de la Junta de Andalucía se reserva la apreciación de otros elementos y circunstancias, que introducen, sin duda, un cierto margen de valoración, no ya reglada ${ }^{42}$. De este modo, podrá suceder que un MT cumpla las exigencias cuantitativas previstas en el art. 2 del Decreto -es decir, sea en términos fácticos un municipio turístico-, pero la Administración de la Junta de Andalucía considere que, a pesar de ello, no merece la calificación formal u oficial de MT. Asimismo, el carácter al menos parcialmente discrecional de esta decisión se ve corroborado por su atribución al Consejo de Gobierno como máximo órgano de gobierno de la Administración autonómica.

De otro lado, a diferencia de los requisitos previos que sólo admiten ser cumplidos o no, los elementos de valoración son susceptibles de modulación. Y teniendo en cuenta que la declaración de MT no comporta unos efectos jurídicos directos, y que el propio Decreto 158/2002 -art. 9.3- permite que en el procedimiento de declaración de MT se especifiquen las carencias de servicios e infraestructuras del municipio que se deben mejorar, y a cuya implantación deberán encaminarse los posteriores convenios interadministrativos, por todo ello debe entenderse que el grado de cumplimiento de los elementos de valoración (especialmente los del apartado 1 del art. 3) no tiene por qué ser perfecto o idóneo para la obtención de la calificación de MT.

\subsection{Esfuerzo presupuestario en la prestación de servicios municipales.}

Enlazando con la referencia de la Ley 12/1999 a los servicios municipales, el Decreto 158/2002 valora, en primer lugar, el esfuerzo presupuestario que realiza el municipio en relación con la prestación efectiva de los servicios municipales mínimos, de conformidad con el artículo 26 de la Ley 7/1985, de 2 de abril, reguladora de las Bases del Régimen Local ${ }^{43}$, "y todos aquellos que

\footnotetext{
42 Por el contrario, J. L. RIVERO YSERN, "Notas sobre la Ley 12/1999, de 15 de diciembre, reguladora del Turismo en Andalucía”, op. cit., p. 205, considera que la decisión del Consejo de Gobierno no es discrecional, sino reglada.

43 Debe observarse que las Comunidades Autónomas con competencias sobre régimen local, hoy en día prácticamente todas, están facultadas para introducir servicios mínimos adicionales a los previstos, con carácter general, en el LBRL, bien añadiendo otros servicios no contemplados en la LBRL, o bien rebajando el segmento de población en relación con los servicios ya previstos en la LBRL. De hecho, la Ley 7/1994 de Protección Ambiental de Andalucía -art. 43-, aun cuando mantuvo el parámetro de 5.000 habitantes para el servicio de tratamiento de residuos, precisó que basta que se supere ese número "con carácter estacional".
} 
tienen repercusión en el turismo respecto a los vecinos y a la población turística asistida". Por tanto, la valoración no se constriñe a los servicios mínimos por imposición legal, sino que se extiende a un conjunto amplio de infraestructuras y servicios públicos, que podrán o no ser de obligatoria prestación en función del número legal de habitantes del Municipio y que, en general, están orientados a acreditar el compromiso del Ayuntamiento en la prestación de unos servicios público de la calidad a los vecinos y turistas ${ }^{44}$.

A tales efectos, el Decreto 158/2002 considera prioritarias las actuaciones y prestación de servicios específicos en una serie áreas, y que podrían clasificarse en dos tipos:

-Infraestructuras y servicios generales: saneamiento y salubridad públicas; servicios de limpieza viaria, de recogida y tratamiento de residuos, alcantarillado y tratamiento de agua residuales; suministro de agua y alumbrado público; protección civil y seguridad en lugares públicos ${ }^{45}$; ordenación del tráfico de vehículos y personas en las vías urbanas; transporte público de viajeros.

-Servicios de interés para la población turística: defensa y restauración del patrimonio cultural y urbano; protección y recuperación del entorno natural y del medio ambiente; actividades o instalaciones culturales y deportivas; ocupación del ocio. El único servicio municipal específicamente turístico previsto es el de información turística ${ }^{46}$. A este respecto, debe entenderse que este servicio de información turística debe prestarse a través de una oficina de turismo integrada en la Red de Oficinas de Turismo de Andalucía, en los términos ordenados en el Decreto 2002/2002, de 16 de julio, de Oficinas de Turismo de Andalucía.

Para acreditar este elemento, el Ayuntamiento deberá presentar una Memoria explicativa acerca de las actuaciones y servicios que presta el municipio respecto a los vecinos y a la población turística asistida en las áreas referidas, así como una descripción de la problemática que presenta la adecuada pres-

\footnotetext{
${ }^{44}$ En este sentido, la Ley de Aragón 6/2003 -art. 15.2- se refiere al esfuerzo presupuestario realizado por el municipio en relación con los servicios municipales obligatorios y de todos aquellos servicios con especial repercusión en el turismo.

45 De un modo más amplio, la Ley 12/1999 se refiere a "seguridad ciudadana".

${ }^{46}$ En este sentido, la Ley de Galicia 9/1997 -art. 8.2- se refiere a la oficina de información turística, al menos, durante la época de mayor afluencia turística.
} 
tación de los servicios enumerados en el punto anterior y proyectos que resultaría necesario abordar, y la información relativa a la liquidación presupuestaria del año anterior a la presentación de la solicitud, con una valoración detallada de ingresos y gastos, tanto de los servicios que efectivamente se prestan, como de los previstos para proyectos y actuaciones futuras, y con expresión de las diversas fuentes de financiación -art. 5.3 Decreto-.

\subsection{Planeamiento urbanístico general.}

El Decreto 158/2002 valora también la existencia en el Municipio de un planeamiento urbanístico general vigente que:

a) Haya sido sometido al trámite de evaluación de impacto ambiental conforme a lo establecido en la Ley 7/1994, de 18 de mayo, de Protección Ambiental de Andalucía, o que contenga una valoración de los efectos medioambientales si se trata de planes anteriores a la aplicación de dicha Ley ${ }^{47}$.

b). Su sistema general de espacios libres cumpla los estándares mínimos de acuerdo con la legislación urbanística, referido a la suma de la población turística asistida ${ }^{48}$. En realidad, este es el único precepto que utiliza la noción legal de población turística asistida, debiendo señalarse que el propio Decreto 158/2002 (disp. adicional única) declara que el cálculo de la población turística asistida se obtendrá mediante la aplicación de la siguiente fórmula: PTA = Número pernoctaciones año/365 + (Número de viviendas de segunda residencia x 3 x 51) /365; donde 3 es igual al número medio de personas por vivienda de segunda residencia y 51 es igual al número medio de días de uso al año de la segunda residencia ${ }^{49}$. Lo cierto es que en este cálculo no se incluyen

\footnotetext{
47 Como es sabido, la Ley 7/1994 de Protección Ambiental de Andalucía incluyó dentro del elenco de actuaciones sometidas a evaluación de impacto ambiental (Anexo Primero), a los Planes Generales de Ordenación Urbana, Normas Complementarias y Subsidiarias de Planeamiento, así como sus revisiones y modificaciones (núm. 20). Y, a este respecto, el Decreto 292/1995, de 12 de diciembre, por el que se aprueba el Reglamento de Evaluación de Impacto Ambiental, precisa que las revisiones y modificaciones deberán someterse a este trámite siempre que introduzcan elementos que afecten sustancialmente al medio ambiente y que no se hubiesen puesto de manifiesto anteriormente en figuras previas del planeamiento (núm. 20 del Anexo).

48 Debe recordarse que la Ley 7/2002, de 17 de diciembre, de Ordenación Urbanística -art. 10- establece que los PGOU deben, como mínimo, contener las reservas precisas para parques, jardines y espacios libres públicos en proporción adecuada para las necesidades sociales actuales y previsibles, que deben respetar el estándar mínimo entre 5 y 10 metros cuadrados por habitante.

49 De modo similar, la Ley de Aragón 6/2003 -art. 15.2- se refiere a la existencia de planeamiento urbanístico, "con especial valoración del sistema de espacios libres".
} 
a los visitantes, a pesar de los términos empleados por la Ley 12/1999 -art. $6.3-$.

c). Prevea la cualificación de las infraestructuras y equipamientos urbanos, reforma interior y mejora urbana de zonas saturadas por el uso turístico residencial. Se trataría, más bien, de una operación de recualificación de destinos turísticos.

d). Contemple planes de accesibilidad para la supresión de barreras arquitectónicas, urbanísticas y en el transporte conforme al el Decreto 72/1992 de 5 de mayo, de normas técnicas para la accesibilidad y la eliminación de barreras arquitectónicas, urbanísticas y del transporte en Andalucía ${ }^{50}$. Lo cierto es que, hoy en día, un turismo de calidad debe ser, necesariamente, un turismo accesible a todos, sin obstáculos y barreras físicas o arquitectónicas ${ }^{51}$.

e). Prevea el tratamiento adecuado de los recursos naturales, y la adaptación de los usos al entorno turístico. Se trata de una determinación imprescindible para garantizar un turismo sostenible. A este respecto cabe señalar que la FEMP dispone de una proyecto denominado de Municipio Turístico Sostenible, cuyo objetivo básico es proporcionar a los Ayuntamientos de municipios turísticos un modelo o sistema de gestión medioambiental, de acuerdo con los requisitos establecidos en el Reglamento Comunitario 761/01 por el que se permite que las organizaciones se adhieran con carácter voluntario a un sistema comunitario de gestión y auditoría ambientales (EMAS). La integración de un municipio en este sistema conlleva el reconocimiento oficial del compromiso del Ayuntamiento con relación a la mejora del medio ambiente. Aunque es, desde luego, una iniciativa voluntaria, es evidente que la Consejería deberá valorar positivamente la adhesión al mismo por parte de un Municipio interesado en la obtención de la calificación de MT.

${ }^{50}$ El Decreto 158/2002 parece olvidar que, tras el Decreto 72/1992 se aprobó la Ley 1/1999, de 31 de marzo, de Atención a las personas con discapacidad en Andalucía, que impone la accesibilidad a la planificación urbanística -arts. 45 y 48.1-, así como planes de supresión de las barreras ya existentes -arts. 49.2 y $55.2-$.

\footnotetext{
${ }^{51}$ En el caso del MT de Benalmádena, la Administración autonómica estimó suficiente la obligación prevista en el Plan General de que en todos los proyectos de edificación y urbanización que se desarrollen al amparo del planeamiento municipal se justifique el cumplimiento del Decreto 72/1992. Sin embargo, este precepto no hace sino reiterar un deber legal ya contenido en la disposición autonómica, de vigencia directa e inmediata. Además, el Decreto 158/2002 se refiere expresamente a "planes de accesibilidad", es decir, a programas de supresión de barreras ya existentes, con indicación de objetivos específicos y recursos asignados.
} 


\subsection{Planeamiento turístico.}

El Decreto 158/2002 valora la existencia de un plan turístico municipal (p. j. un Plan de Excelencia Turística) o instrumento de planificación turística similar aprobado por el Pleno con una duración no inferior a la cuatrienal -lo cual supone un compromiso sostenido en el tiempo adoptado por el órgano más representativo de la Corporación municipal-, con el siguiente contenido mínimo:

a). "El diagnóstico de la situación turística del municipio: recursos y servicios turísticos disponibles y carencias detectadas".

b). "La propuesta de actuaciones para mejorar la calidad del turismo en el municipio". A este respecto, debe señalarse que la base de toda estrategia turística local radica en que el gasto del turista se efectúe en el mayor porcentaje posible en el municipio, y de aquí la conveniencia de contar con una oferta de servicios turísticos adecuada, y, en particular, de establecimientos alojativos, puesto que constituyen la oferta turística básica sobre la que en buena medida se asienta y hace posible todo el resto de actividades.

c). "La valoración económica de la propuesta, expresando la cuantía imputada al presupuesto municipal y, en su caso, la previsión de otras fuentes de financiación". En este último caso se expresarán, cuando proceda, los compromisos de otras Administraciones públicas y entidades públicas o privadas de colaborar con el municipio a través de la suscripción o adhesión a los convenios previstos en el presente Decreto.

En este punto, tal vez debería haberse tenido presente el grado de adecuación del Plan municipal de turismo al Plan General de Turismo, al cual le corresponde definir el modelo y la estrategia para desarrollo turístico de la Comunidad Autónoma -art. 15.1 Ley 12/1999-, todo ello de acuerdo con el art. 59.1 de la Ley Básica de Régimen Local ${ }^{52}$.

\subsection{Espacios Naturales Protegidos.}

Por último, el Decreto 158/2002 (si bien en la sistemática del Decreto es en segundo lugar) menciona la circunstancia según la cual en el término mu-

\footnotetext{
52 Sobre el Plan General de Turismo, vid. R. M플 ILDEFONSO HUERTAS, "Las políticas de turismo en la Comunidad Autónoma de Andalucía”, op. cit., pp. 191 y ss.
} 
nicipal se encuentre ubicado, total o parcialmente, alguno de los Espacios Naturales Protegidos de Andalucía ${ }^{53}$, circunstancia que, por otra pare, no es modo alguno excepcional en nuestra Comunidad Autónoma, dada la considerable extensión en la misma de la red de espacios naturales protegidos ${ }^{54}$. Es decir, lo que viene a valorarse es que el Municipio cuente con un recurso o bien natural de especial interés, y que en otros ordenamientos es calificado expresamente como "recurso turístico esencial"55.

Sin embargo, debe observarse que este elemento a valorar es cualitativamente diverso a los anteriores. En efecto, el esfuerzo presupuestario en la prestación de servicios de competencia municipal, el cumplimiento de las exigencias legales en la ordenación urbanística municipal y la programación en un documento oficial de la política turística municipal, son actuaciones imputables al Ayuntamiento interesado, en las que se acredita el compromiso efectivo de la Corporación Local en la calidad de los servicios e infraestructuras municipales. En cambio, este otro elemento hace referencia a la circunstancia de la existencia en el Municipio de un recurso turístico relevante, circunstancia que es evidentemente por completo ajena a la trayectoria de la política municipal ${ }^{56}$, y que se trata más bien de un elemento más propio del concepto de municipio o comarca de "interés turístico", que de la noción de MT en su sentido original. En efecto, la presencia de recursos turísticos relevantes en el municipio se tenía en cuenta de un modo indirecto o reflejo, en función de su capacidad efectiva para atraer una gran afluencia de visitantes, que era

\footnotetext{
${ }^{53}$ Debe recordarse que, además de las figuras ordenadas en la Ley 4/1989, de 27 de marzo, de Conservación de los Espacios Naturales y de la Flora y Fauna Silvestres (Parques, Reservas Naturales, Monumentos Naturales y Paisajes Protegidos), la Ley 2/1989, de 189 de julio, de Espacios Naturales Protegidos de Andalucía establece -art. 2- otros regímenes de protección adicionales (Parajes Naturales, Parques Periurbanos y Reservas Naturales Concertadas).

${ }^{54}$ Tan sólo los Parques Naturales (el 91\% de la superficie total) suponen en Andalucía una superficie cercana al millón y medio de hectáreas, alrededor del $17 \%$ de la superficie de la Comunidad Autónoma, dato que contrasta con el poco más del 7\% del total en el conjunto de España. Vid. J. M. AYLLÓN DÍAZ-GONZÁLEZ, "Balance y perspectivas de la protección del medio natural en Andalucía", Rev. Andaluza de Administración Pública, número extraordinario 2/2003, volumen 2, p. 397.

55 Ley de Cataluña 13/2002 de Turismo -art. 5.2-.

${ }^{56}$ Parece ocioso recordar que la declaración de los espacios naturales protegidos corresponde a las Comunidades Autónomas y al Estado -arts. 21.1 y 22.2 Ley 4/1989 de Conservación de los Espacios Naturales y de la Flora y Fauna Silvestres-.
} 
el dato relevante, independientemente de la naturaleza del recurso turístico -ambiental, cultural, de ocio...-.

Se trata, asimismo, de un criterio que tiene difícil encaje en el art. 7 de la Ley 12/1999, que -como nos consta- únicamente alude a actuaciones municipales, si bien dado que no constituye un requisito previo sino un elemento más a valorar, no parece que pueda considerarse como una determinación contraria a la Ley ${ }^{57}$. Por otro lado, aunque se admita la corrección y conveniencia de este criterio, en tal caso no se entiende la razón de que se haya restringido la valoración a los recursos turísticos naturales. Por idéntica razón, podría haberse incluido también la existencia en el Municipio de bienes culturales de interés nacional e, incluso, protegidos por declaraciones de organismos internacionales -como es el caso de las ciudades declaradas patrimonio de la humanidad, distintivo al que se han sumado recientemente en Andalucía las ciudades de Baeza y Úbeda $-{ }^{58}$.

\section{PROCEDIMIENTO PARA LA DECLARACIÓN DE MT.}

En general, puede observarse que el Decreto 158/2002 ordena un procedimiento adornado de las típicas garantías administrativas pensadas para los ciudadanos en sus relaciones con las Administraciones Públicas -solicitudes, audiencias, plazos de resolución...-, cuando lo cierto es que se trata de una relación interinstitucional. Sin embargo, este proceder puede estimarse acertado, pues de este modo se garantiza un tratamiento no discriminatorio y leal por parte de la Administración autonómica en una actividad que tiene relevantes efectos en orden a la distribución territorial de los recursos públicos. Por el contrario, como se verá, una vez otorgado el calificativo de MT, se inicia una fase de relaciones de cooperación, presididas por la técnica del acuerdo o concertación bilateral.

\footnotetext{
${ }^{57}$ La introducción de este elemento tal vez puede obedecer a la finalidad de evitar la oposición por parte de determinados Gobiernos municipales a la declaración en su territorio de espacios naturales protegidos, que se ven como un obstáculo para su desarrollo económico, y, en particular, para su desarrollo turístico.

58 Así, la Ley de Aragón 6/2003 -art. 15.2- se refiere, de un modo general, a la "relevancia de los recursos turísticos existentes en el término municipal”.
} 


\subsection{Inicio del procedimiento.}

Aun cuando en alguna Comunidad Autónoma se contempla la posibilidad de inicio de oficio ${ }^{59}$, con buen sentido, la Ley $12 / 1999$ y el Decreto 158/2002 establecen que el procedimiento para la declaración de Municipio Turístico se iniciará mediante la solicitud del municipio interesado, el cual deberá cumplir los requisitos previos antes mencionados.

De otro lado, siguiendo el criterio de alguna Comunidad Autónoma ${ }^{60}$, tanto la Ley 12/1999 -art. 7.2- como el Decreto 158/2002 -art. 4.3-, establecen que la solicitud será formulada por el Alcalde del Ayuntamiento, "previo acuerdo plenario del Ayuntamiento adoptado por mayoría absoluta del número legal de miembros de la Corporación”, lo cual deberá ser acreditado mediante la correspondiente certificación -art. 5.1 Decreto 158/2002-. A este respecto, si bien parece procedente que la iniciativa sea respaldada por el Pleno de la Corporación, debido al esfuerzo continuado que implica la declaración de MT, no se entiende bien la exigencia de una mayoría cualificada. La propia exposición de motivos del Decreto justifica esta exigencia de mayoría absoluta del Pleno en el respeto a la autonomía municipal. Sin embargo, no se comprende por qué razón la imposición de una mayoría cualificada es más respetuosa con la autonomía municipal, cuando lo que se está es imponiendo una exigencia adicional.

Pero, además de inconsistente, se trata de una exigencia de dudosa constitucionalidad, a la luz de la doctrina del Tribunal Constitucional -SSTC 33/1993, 331/1993-, pues altera el modelo de democracia local por mayorías simples establecido con carácter básico por la Ley estatal. En la economía legal de la LBRL los supuestos tasados de mayorías cualificadas tienen un marcado carácter estructural -adhesión a un Mancomunidad, delegación de una competencia, segregación del término...-, y pudiera, por ello, tener sentido, si la calificación de MT supusiera realmente la sujeción del Municipio a un estatuto particular, pero -como nos consta- no es así, al menos en el ordenamiento andaluz: la calificación de MT carece de efectos estructurales, puesto que se reconducen al campo, más moldeable o dúctil, de la concertación con la Administración autonómica. Por ello parece mejor el criterio seguido la Ley de Galicia 9/1997 -art. 8.3- de exigir el acuerdo plenario, pero sin imponer una mayoría cualificada.

\footnotetext{
${ }^{59}$ Ley de Galicia 9/1997 -art. 8.3-.

${ }^{60}$ Ley de la Comunidad Valenciana 3/1998 -art. 29.1-.
} 
Por lo demás, el Decreto 158/2002 -art. 4.4- dispone que la solicitud junto con la documentación que acredita el cumplimiento de los requisitos y los elementos a ponderar debe dirigirse a la correspondiente Delegación Provincial de Turismo y Deporte y se presentará preferentemente en su registro de documentos, sin perjuicio de la utilización de cualquiera de los lugares previstos en el artículo 38.4 de la LRJPAC ${ }^{61}$.

Si la solicitud fuera defectuosa o la documentación incompleta, la correspondiente Delegación Provincial de Turismo y Deporte requerirá al Ayuntamiento solicitante para que en el plazo de diez días subsane las faltas o acompañe los documentos necesarios -art. 6.1 Decreto-. En el supuesto de que la no presentación de los mismos imposibilite continuar el procedimiento, se le indicará expresamente advirtiéndole que se le tendrá por desistido, emitiéndose una resolución en los términos del artículo 42.1 de la LRJPAC ${ }^{62}$. Asimismo, la Delegación Provincial podrá recabar del solicitante la modificación o mejora voluntaria de la solicitud, "así como cuanta documentación complementaria y probatoria estime pertinente para una mejor justificación del expediente, concediéndole un plazo de diez días" 63 .

\subsection{Instrucción del procedimiento.}

Los principales trámites de la instrucción del procedimiento son los siguientes:

\footnotetext{
${ }^{61} \mathrm{Al}$ igual que otras reglamentaciones procedimentales, se establece que las solicitudes deben dirigirse "preferentemente" al órgano concreto competente para instruir el procedimiento. En mi opinión, se trata de disposiciones perturbadoras, pues producen el efecto (probablemente deseado) de que si la solicitud se presenta a otro registro -en ejercicio, por otra parte, del derecho que reconoce la Ley- podrá ser objeto de algún tipo de preterición. Y nada más lejos del espíritu de la Ley, la cual ya ha tenido en cuenta este mecanismo disociando la fecha de presentación de la solicitud en el registro -que será válida a los efectos del cumplimiento de plazos por los interesados (art. 4.1 RD 772/1999) - de la fecha de inicio del procedimiento -arts. 42.3.b) LPAC, art. 4.2 RD 772/1999-. Por tanto, conviene que este tipo de añadidos desaparezcan de las normas procedimentales.

${ }^{62}$ Como es sabido, la reforma operada por la Ley 4/1999 introdujo en la LRJPAC el deber de dictar resolución también en estos casos de desistimiento presunto.

63 Se trata de una cláusula prevista en otras normas, como el Decreto 202/2002, de 16 de julio, de Oficinas de Turismo de Andalucía, en relación con el procedimiento de inscripción de estas Oficinas -art. 11.2-. Estas cláusulas son de dudosa conformidad con el derecho proclamado en el art. 35.f) de la LRJPAC, pues una garantía para el administrado -como es la mejora voluntaria- es utilizada - perversamente- como apoyo a una potestad de la Administración -la de requerir documentación adicional al interesado-.
} 
- Informe preliminar de la Delegación Provincial. Dado el carácter reglado de los requisitos previos establecidos en el Decreto, cuyo cumplimiento no requiere más que la verificación de los documentos previstos en la norma, el Decreto atribuye esta función a las Delegaciones Provinciales. En efecto, la Delegación Provincial, tras analizar la solicitud y, en su caso, practicar las pruebas que sean necesarias, debe pronunciarse sobre el cumplimiento alguno de los requisitos previos establecidos en el artículo 2 del Decreto. En el caso de que considere que la solicitud no acredita el cumplimiento de ninguno de los requisitos previos indicados, podrá inadmitirla a trámite -art. 6.5 Decreto-, por reputarse como solicitud "manifiestamente carente de fundamento" -art. 89.4 LRJPAC-. En otro caso, deberá remitir el expediente completo a la Dirección General de Planificación Turística en el plazo de un mes a partir de recibir la solicitud y la documentación, en su caso, recabada, acompañándolo de un informe en el que exprese si concurre alguno de los requisitos previos establecidos en el artículo 2 del Decreto -art. 7 Decreto-.

-Informe evaluador de la Dirección General. Una vez constatado que el municipio cumple alguno de los requisitos, la Dirección General de Planificación Turística debe analizar el grado de concurrencia de los elementos de valoración del artículo 3 del Decreto, emitiendo un informe evaluando turísticamente su alcance y su adecuación a los fines propios del Municipio Turístico -art. 8 del Decreto-. Curiosamente, el Decreto no fija un plazo para la evacuación de este informe ${ }^{64}$.

-Informe del Consejo Andaluz del Turismo. La Dirección General debe trasladar el expediente al Consejo Andaluz del Turismo, órgano consultivo y de asesoramiento de la Administración de la Junta de Andalucía en materia de turismo -art. 10.1 Ley 12/1999-, a efectos de que emita un informe (preceptivo) sobre la procedencia de la solicitud -art. 6.2 Ley 12/1999 y art. 9.1 Decreto $158 / 2002-65$. El informe deberá examinar la procedencia de la declaración de Municipio Turístico según los elementos de valoración, es decir, sobre la misma cuestión que previamente se ha pronunciado la Dirección General

\footnotetext{
64 Ciertamente, el art. 83.2 de la LRJPAC establece un plazo supletorio de 10 días, pero parece evidente que es un plazo excesivamente breve para la elaboración de un informe tan complejo como el que requiere el Decreto 158/2002.

${ }^{65}$ Esta atribución se encuentra también contenida en el Decreto 21/2002, de 29 de enero, por el que se regula la organización y funcionamiento del Consejo Andaluz de Turismo -art. 2.1-, así como en la Orden de 18 de octubre de 2002, por la que se aprueba su Reglamento de Régimen Interior -art. 9.1-.
} 
de Planificación Turística, cuyo titular es también miembro del Consejo. Pero, además, el Decreto 158/2002 añade que el Consejo Andaluz del Turismo formulará una propuesta (hay que entender en el caso de que se informe favorablemente) "acerca de las necesidades derivadas de la declaración, sobre los servicios turísticos municipales que hay que potenciar y las carencias de servicios e infraestructuras del municipio que se deben mejorar y a cuya implantación deben encaminarse los convenios regulados en el Decreto, todo ello en función del tipo de destino turístico de que se trate" 66 . Esta posibilidad que abre el Decreto permite pensar que es perfectamente posible que la resolución de estimación sea condicionada al cumplimiento de los objetivos señalados en el informe. Por lo demás, el Decreto -art. 9.6- precisa que el informe, que debe ser evacuado en el plazo de dos meses ${ }^{67}$, tiene carácter preceptivo "y determinante" para la resolución del procedimiento ${ }^{68}$.

-Audiencia. Sin perjuicio de la posibilidad de que el Consejo Andaluz del Turismo considere conveniente ofrecer al municipio interesado su comparecencia ante el órgano -art. 9.5 Decreto-, de conformidad con la LRJPAC -ar. 84.1-, una vez instruido el procedimiento e inmediatamente antes de redactar la propuesta de resolución, la Dirección General de Planificación Turística pondrá de manifiesto el expediente al municipio para que, en el plazo no inferior a diez ni superior a quince días, pueda presentar los documentos o alegaciones que estime pertinentes ${ }^{69}$.

-Propuesta. Transcurrido el plazo de audiencia y una vez valoradas por la Dirección General las alegaciones presentadas, el titular de la Consejería de

\footnotetext{
${ }^{66}$ A este respecto debe recordarse que el propio Decreto 158/2002 -art. 2.1- admite un destino "mixto" de turistas que realizan pernoctaciones en alojamientos turísticos y de "visitantes".

${ }^{67}$ En el supuesto de que el expediente estuviera incompleto o el Consejo Andaluz del Turismo considerara necesario realizar alguna actuación, probatoria o no, sin la cual no pueda emitir el informe, lo recabará de la Dirección General, quedando suspendido el plazo para emitir el informe -art. 9.2-.

68 Como es sabido, en estos casos de informes preceptivos que sean determinantes para la resolución del procedimiento, el órgano actuante "podrá" -debería decir "deberá"- interrumpir el plazo de los trámites sucesivos -art. 83.3 LRJPAC-. En todo caso, tras la Ley 4/1999, se establece que deberán comunicarse a los interesados (en este caso al Municipio solicitante) la petición del informe y, en su caso, su recepción, y el plazo de suspensión no podrá exceder en ningún caso de tres meses -art. 42.5.c) LRJPAC-.

${ }^{69}$ De modo similar, Decreto del Consejo de Gobierno de Galicia 39/2001 -art. 14.5-.
} 
Turismo y Deporte formulará al Consejo de Gobierno una propuesta estimatoria o desestimatoria de la solicitud de declaración de Municipio Turístico.

En relación con este procedimiento, pueden realizarse algunas observaciones. En primer lugar, pese al alcance horizontal de la calificación de MT, puesto que está llamada a afectar a diversos Departamentos del Gobierno andaluz a través de los posteriores convenios interadministrativos, llama la antención la falta de participación del Consejo de Coordinación Interdepartamental en materia de turismo, como órgano de coordinación y consulta interna de la Administración de la JA -art. 11.1 Ley 12/1999-. Con todo, es posible que se haya pensado que esa coordinación puede alcanzarse a través de los representantes de las Consejerías miembros del Consejo Andaluz de Turismo, con economía de trámites ${ }^{70}$. No obstante, independientemente de la participación general de las Consejerías a través del órgano colegial que corresponda, tal vez debería de haberse previsto una participación especial, a través de un informe, de la Consejería de Gobernación, como departamento competente, con carácter horizontal, en materia de cooperación territorial, y tal como se prevé en alguna Comunidad Autónoma ${ }^{71}$.

De otro lado, es llamativa la ausencia de participación de la Diputación Provincial correspondiente, cuya intervención se contempla en otras Comunidades Autónomas ${ }^{72}$. Y si bien puede convenirse que la Corporación Provincial no se encuentra legalmente "afectada", dado que no se trata de un asunto supramunicipal ni la calificación de MT supone cambio alguno de régimen o estatuto del Municipio, no deja de ser llamativa la ausencia de la principal institución pública de cooperación con los municipios, en lo que es básicamente un proyecto de cooperación interinstitucional para la mejora de los ser-

\footnotetext{
${ }^{70}$ De acuerdo con el Decreto 21/2002, integran el Consejo Andaluz de Turismo, entre otros, representantes de las Consejerías de Economía, Administración Local, Ordenación del Territorio y Urbanismo, Medio Ambiente, Cultura, Consumo, Empleo y Agricultura -art. 4-. Además, el Decreto 21/2002 prevé que cuando figuren en el orden del día asuntos que sean competencia de Consejerías que no posean un miembro en el Consejo Andaluz de Turismo, serán convocadas para que puedan asistir a la reunión mediante un representante, el cual actuará con voz y sin voto.

${ }^{71}$ Ley de Cataluña 13/2002 -art. 21.1-. Por otra parte, llama la atención de la descoordinación del Gobierno andaluz en esta materia, pues el Anteproyecto de Ley de Cooperación Territorial, elaborado desde la Consejería de Gobernación, ignora por completo una figura tan importante para la cooperación local como la declaración de MT.

${ }^{72}$ Decreto de Galicia 39/2001 -art. 14.2-. La Ley de Aragón 6/2003 -art. 15.3- ordena el informe preceptivo de la Administración de la comarca a la que pertenezca el municipio solicitante.
} 
vicios municipales, y que podría permitir la integración de la Diputación Provincial en los posteriores convenios interadministrativos, en relación con los cuales se prevé expresamente la posible participación de otras Administraciones Públicas -art. 13.1 Decreto 158/2002-.

Por último, debe observarse que en otras Comunidades Autónomas se ha ordenado un tramite de información pública ${ }^{73}$, ausente en el Decreto 158/2002, si bien, por el ámbito de la declaración, parecería más razonable que tal trámite se efectuase por el Municipio antes que por la Administración autonómica.

\subsection{Resolución del procedimiento.}

De acuerdo con una pauta mayoritaria, corresponde al Consejo de Gobierno de la JA la resolución del procedimiento de declaración de Municipio Turístico -art. 6.2 Ley 12/1999-, criterio razonable debido al alcance transversal de esta declaración ${ }^{74}$. El Acuerdo del Consejo de Gobierno que ponga fin al procedimiento será notificado al interesado en el plazo de seis meses desde que la solicitud tuviera entrada en el registro de la correspondiente Delegación provincial de Turismo y Deporte.

Transcurrido dicho plazo sin haberse practicado la notificación, podrá entenderse desestimada la solicitud, de acuerdo con lo dispuesto en el artículo 2 de la Ley 9/2001, de 12 de julio, por la que se establece el sentido del silencio administrativo y los plazos de determinados procedimientos como garantías procedimentales para los ciudadanos (Anexo II). En general, tanto el plazo del procedimiento como el sentido del silencio administrativo pueden estimarse adecuados, dada, de un lado, la complejidad de la tramitación de este procedimiento, en el que deben valorarse por diversas instancias elementos complejos y, de otro lado, la falta de operatividad del silencio estimatorio en este procedimiento, pues la declaración MT, en sí misma, carece de efectos directos -como se verá seguidamente- ${ }^{75}$.

\footnotetext{
${ }^{73}$ Ley de la Comunidad Valenciana 3/1998 -art. 29.2-.

${ }^{74}$ En este sentido, Ley de Galicia 9/1997 -art. 8.3-; Ley de la Región de Murcia 11/1997 -art. 51-, Ley de la Comunidad Valenciana 3/1998 -art. 29.3-, Ley de Cataluña 13/2002 -art. 21.1-. De este criterio se separa la Ley de Aragón 6/2003 -art. 15.3-, la cual atribuye la competencia al Departamento competente en materia de turismo.

75 Así, ambas determinaciones coinciden con las previstas en el Decreto de Galicia 39/2001 -art. 16.2-.
} 
De otro lado, aun cuando no lo explicite el Decreto 158/2002, debe entenderse que la resolución expresa desestimatoria debe ser motivada -art. 54.1.f) LRJPAC-. Por lo demás, los Acuerdos de declaración de Municipios Turísticos serán publicados en el Boletín Oficial de la Junta de Andalucía -art. 12.3 Decreto 158/2003-76.

\subsection{Efectos de la declaración de MT.}

La Ley 12/1999 -art. 8, que lleva por rúbrica "Efectos de la declaración”-, dispone que la declaración de MT "podrá" dar lugar a la celebración de convenios interadministrativos en orden a compensar la mayor onerosidad en la prestación de los servicios. Sin embargo, el Proyecto de Ley era más preciso pues, en la línea de otras normas autonómicas ${ }^{77}$, contemplaba expresamente varias previsiones: a) la inclusión del municipio con carácter preferente en las acciones de ordenación y fomento derivadas del Plan General de Turismo; b) su consideración en las acciones de ordenación y fomento de los planes sectoriales de la Junta de Andalucía; c) el acceso a una línea específica de ayudas y subvenciones con cargo a los Presupuestos de la Comunidad Autónoma; d) el establecimiento, por dicho municipio, de recursos específicos conforme a la legislación de haciendas locales ${ }^{78}$. Sin embargo, en virtud de una enmienda del G.P. Socialista, se suprimieron estas medidas, dando lugar a la redacción actual, en la que la entera eficacia de la declaración queda remitida a los convenios que puedan acordarse ${ }^{79}$.

A este respecto, el Decreto 158/2002 -art. 12.1- prevé que en caso de concederse la declaración, la resolución conllevará, "además de los efectos atribuidos por la legislación vigente” (efectos que ni la Ley ni el Decreto pre-

\footnotetext{
${ }^{76}$ Debe señalarse que, a diferencia de lo establecido en otras Comunidades Autónomas -caso del art. 29.3 de la Ley de la Comunidad Valenciana 3/1998-, este acuerdo del Consejo de Gobierno no reviste la forma de Decreto, de tal modo que esta publicación presenta una finalidad de transparencia de este tipo de actuaciones, pero no es condición de eficacia del acuerdo, sino que el mismo surtirá efectos a partir de su notificación a la entidad interesada.

${ }^{77}$ Ley de Galicia 9/1997 -art. 8.4-.

78 BOPA núm. 351, 30 de julio de 1999. El Consejo Consultivo de Andalucía ya había indicado la conveniencia de mejorar la redacción del texto legal para evitar una posible incorrecta interpretación que vinculara el establecimiento de recursos específicos por parte de los Municipios a la celebración de un convenio, lo que atentaría a la autonomía local.

${ }^{79}$ Enmienda núm. 145. BOPA núm. 383, 5 de noviembre de 1999.
} 
cisan), la simple "posibilidad" de suscribir convenios. Y, reitera el Decreto 158/2002 -art. 13.1- que la declaración de Municipio Turístico "podrá dar lugar a la celebración de convenios”. Ciertamente, la Ley 12/1999 -art. 8- se refiere también a los celebración de convenios como una posibilidad, pero ello tenía su explicación en la redacción inicial del Proyecto de Ley, la cual incluía -como se ha señalado- determinados efectos "ope legis" de la declaración. Pero una vez que los efectos automáticos han desaparecido, tal vez debió reconsiderarse la redacción de este precepto, imponiendo, al menos, al Gobierno autonómico el deber de realizar una "oferta" de convenio al Municipio que se declara MT, y fijando unos plazos máximos.

$\mathrm{Al}$ no hacerse así, se observa un cierto desequilibrio entre la exigencia a los Municipios interesados en la declaración de superación de una serie de requisitos previos y de condiciones ciertamente rigurosos, para seguidamente remitir en bloque a la negociación bilateral los beneficios que pueda reportar la declaración. Como suele decirse, tal vez, para este camino no hacían falta aquellas alforjas. Y, desde otra perspectiva, de poco sirve para la transparencia en la distribución de los recursos públicos establecer un riguroso procedimiento de concesión, si después el reparto de los fondos se efectúa en negociaciones bilaterales, sin ningún condicionamiento o parámetro general, tal y como se establece en la Comunidad Valenciana ${ }^{80}$. La única manifestación de transparencia en este ámbito sería la publicación de los convenios, tal como ordena la LRJPAC -art. 8.2-.

Asimismo, el Decreto 158/2002 renuncia a ordenar un régimen especial de los MT, ni siquiera en los términos marcadamente flexibles y minimalistas previstos en otras normas autonómicas - caso de creación de Consejos Sectoriales de Turismo- ${ }^{81}$. Este criterio del ordenamiento andaluz, de reenviar en su integridad los deberes específicos que sumen los MT a lo que se pacte en

\footnotetext{
${ }^{80}$ Por Decreto 71/2000, de 22 de mayo, se regulan los convenios previstos en la Ley 3/1998 de Turismo con los Municipios turísticos, e, incluso, por normas posteriores se fijan los indicadores mínimos que permiten a los Municipios conocer la cuantía sobre la que se aplicará la correspondiente compensación financiera (resolución de la Agencia Valenciana de Turismo de 12 de junio de 2000).

${ }^{81}$ Así, la Ley de Aragón 6/2003 -art. 15.5- prevé que podrá existir en los MT un Consejo Sectorial de Turismo en el que participarán, en todo caso, las organizaciones empresariales y sociales representativas del sector turístico en el ámbito del término municipal. Si bien, lo cierto, es que tal posibilidad existe de suyo en cualquier Municipio, declarado o no turístico, por simple aplicación del ROF y de la potestad autoorganizatoria de las Corporaciones Locales.
} 
cada caso y en cada uno de los múltiples convenios que puedan suscribirse, se separa también de los específicos deberes legales ordenados directamente en el ordenamiento catalán ${ }^{82}$. Ni siquiera se impone a los MT la vinculación a las directrices programáticas contenidas en el Plan General de Turismo, tal como se prevé en el ordenamiento gallego ${ }^{83}$.

De este modo, la declaración de MT no comporta de forma automática efecto alguno, salvo alguna disposición muy marginal prevista en normas extraturísticas ${ }^{84}$. Su único efecto es abrir la vía de la concertación de la actividad de fomento ${ }^{85}$.

\footnotetext{
82 Así, la Ley de Cataluña 13/2002 -art. 19-impone a los MT una serie de servicios mínimos adicionales a los ya previstos, con carácter general, en la legislación de régimen local. Algunos son de carácter general -como los referidos a la salubridad pública o a la seguridad ciudadana-, y otros son de carácter específicamente turísticos -como los servicios de señalización e información turísticas-.

${ }^{83}$ Decreto de Galicia 39/2001 -art. 17.1-.

${ }^{84}$ Así, la Orden de la Consejería de Gobernación de 25 de marzo de 2002, por la que se regulan los horarios de apertura y cierre de los establecimientos públicos, establece un régimen especial de horarios (más amplios que los previstos en el régimen general), entre otros, para los establecimientos de hostelería y restauración situados en municipios que hayan obtenido la declaración de MT -art. 5.1-. De modo similar, de acuerdo con la Ley Orgánica 2/1996, de 15 de enero, disfrutan del régimen de libertad horaria los establecimientos instalados, entre otros, en "zonas de gran afluencia turística". La Ley Orgánica precisa que la determinación de las "zonas turísticas", así como los períodos a que se contrae la aplicación de la libertad de apertura en las mismas corresponderá a cada Comunidad Autónoma para su respectivo ámbito territorial. A este respecto, la Ley de Comercio Interior de Andalucía -art. 20.2- considera "zonas de gran afluencia turística" los términos municipales o parte de los mismos en los que, en determinados períodos del año, la media ponderada anual de población sea significativamente superior al número de residentes o en los que tenga lugar una gran afluencia de visitantes por motivos turísticos. En dichas zonas, la libertad de apertura sólo será aplicable en los períodos del año que se determinen. Vid. A. CALONGE VELÁSQUEZ- H. VILLAREJO GALENDE, "Municipios turísticos y horarios comerciales”, III Congreso Universidad y empresa, Tirant lo blanch, Valencia, 2000, pp. 343 y ss.
}

${ }^{85}$ Una crítica a esta indeterminación en P. L. MARTÍNEZ PALLARÉS, "El gobierno local como ámbito de gestión turística", en III Congreso Universidad y empresa, Tirant lo blanch, Valencia, 2000 , p. 81. Una manifestación colateral de esta nula eficacia directa de la declaración de MT tuvo lugar en el procedimiento de elaboración de dicha disposición. En efecto, a la hora de cumplir con el trámite de preparación de la memoria económica sobre los costes de aplicación de la norma -en cumplimiento de lo preceptuado en el art. 22.2 de la Ley del Gobierno, de aplicación supletoria-, la Consejería se limitó a señalar que la adopción de la disposición no supondrá, por sí misma, incremento de gastos o disminución de ingresos. ¡Desde luego que la aprobación de ésta y ninguna otra norma supone, por sí sola, gastos adicionales!, pero ¿qué sucede con su aplicación, consistente fundamentalmente en transferencias económicas de la Administración autonómica a los Municipios?. En todo caso, este es un ejemplo más de la tradicional banalización de este trámite del procedimiento de elaboración de disposiciones generales. 


\section{CONVENIOS INTERADMINISTRATIVOS}

\subsection{La organización de los convenios.}

Según el Decreto 158/2002 -art. 12.1-, el Acuerdo del Consejo de Gobierno de declaración de MT debe precisar las líneas básicas de los convenios que, en su caso, se suscriban, las Consejerías que deben participar en los mismos, y la creación y composición del superior órgano de seguimiento de todos los convenios que puedan suscribirse para cada Municipio Turístico. Asimismo, el Decreto 158/2002 -art. 13.1- reitera que formarán parte de los convenios, además del municipio beneficiario de la declaración, las Consejerías que haya determinado el acuerdo del Consejo de Gobierno, "así como otras Administraciones públicas y entidades públicas o privadas que puedan adherirse", como podría ser el caso de la Diputación Provincial o de la Administración General del Estado ${ }^{86}$.

De este modo, el Decreto 158/2002 ha optado, en lugar de un convenio marco entre el conjunto de la Administración autonómica y el Municipio, sin perjuicio de la suscripción de acuerdos desarrollo del mismo, por un fraccionamiento de la cooperación en múltiples convenios departamentales, y que constituye el último eslabón de una cadena de remisiones a la hora de dar contenido a la declaración de MT. El único factor de unidad es el "superior órgano de seguimiento de todos los convenios", cuya composición debe ser determinada por el Acuerdo del Consejo de Gobierno de declaración de $\mathrm{MT}^{87}$.

\subsection{Fines de los Convenios.}

De acuerdo con la Ley 12/1999 -art. 8-, los convenios irán encaminados a compensar la mayor onerosidad en la prestación de los servicios, y a tal efecto establecerán medidas para alcanzar, al menos, los siguientes fines (art. 13.2 Decreto):

\footnotetext{
${ }^{86}$ Sin embargo, lo cierto es que en la declaración del MT de Benalmádena únicamente se contempló expresamente la suscripción de convenios entre Consejería de Turismo y Deporte y el Ayuntamiento, lo cual supone rebajar considerablemente el alcance y virtualidad de la institución.

${ }^{87}$ En el caso de la declaración del MT de Benalmádena, la comisión de seguimiento está integrada por cuatro representantes de la Consejería de Turismo y Deporte, cuatro representantes del Ayuntamiento, y un representante de cada Consejería que suscriba convenios con el Ayuntamiento.
} 
a) Mejorar las condiciones de salubridad pública, protección civil y seguridad en lugares públicos.

b) Proteger los valores tradicionales y culturales de la población autóctona.

c) Salvaguardar el medio ambiente y los valores ecológicos de Andalucía.

d) Preservar los bienes públicos y privados relacionados con el turismo municipal.

e) Aumentar, diversificar y mejorar la oferta turística complementaria, así como crear nuevos productos.

f) Sensibilizar e implicar a la población y a los agentes locales en una cultura de calidad de vida.

\subsection{Contenido de los convenios.}

Los convenios, suscritos por el municipio, las Consejerías y, en su caso, las entidades privadas y públicas interesadas en su objeto, contendrán las siguientes previsiones:

a) Duración del convenio, tal como exige el art. 6.2 LRJPAC.

b) Las implicaciones económicas del convenio, especificando para cada una de sus anualidades de vigencia, los compromisos financieros de las partes que lo suscriban y, en su caso, de las que con posterioridad se adhieran.

c) Los indicadores del logro de los objetivos y, en su caso, las medidas a adoptar para corregir posibles desvíos sustanciales.

d) En su caso, la necesidad de una organización común para su gestión, tal como se prevé en el art. 6.2 LRJPAC, organización que podrá revestir la forma de consorcio o sociedad mercantil -art. 6.5 LRJPAC-.

e) Los mecanismos de seguimiento, evaluación y modificación del convenio -art. 6.3 LRJPAC-. Para ello se creará un órgano especial que, sin perjuicio de las competencias del órgano superior de seguimiento de los convenios , tendrá como función velar por el cumplimiento efectivo del contenido del convenio así como proponer cuantas medidas crea oportunas para el buen desarrollo de la actividad turística en el municipio.

Por lo demás, los Convenios deberán publicarse en el Boletín Oficial de la Junta de Andalucía, de acuerdo con lo previsto en el art. 8.2 LRJPAC. 


\subsection{Obligaciones de los municipios.}

El Decreto 158/2002 -art. 15.1- declara que los municipios deberán llevar a cabo actuaciones dirigidas a mejorar los servicios públicos a que se refiere el artículo 3 del Decreto, "pudiendo ser objeto de los convenios, entre otras, el establecimiento de medidas para ejecutar programas que potencien y promocionen los recursos turísticos". Lo cierto es que en este inciso no se impone deber alguno, sino únicamente se identifica un posible objeto de los convenios a celebrar. Más aún, el único deber sustantivo enunciado, en el sentido de llevar a cabo actuaciones dirigidas a mejorar los servicios públicos municipales, en realidad es precisamente el objeto prioritario de los convenios, de acuerdo con el art. 13.2 del Decreto.

Por lo demás, el Decreto -art. 15.3- se limita a ordenar diversos deberes instrumentales de información. Así, los Municipios Turísticos deben suministrar a la correspondiente Delegación Provincial de la Consejería de Turismo y Deporte todos los meses, o con la periodicidad que aquella pueda determinar, los datos relativos a la afluencia turística registrada en el municipio, así como cualquier otra información que le sea solicitada relativa a los requisitos y condiciones que motivaron la declaración ${ }^{88}$. En el supuesto de producirse una modificación que implique el incumplimiento de los requisitos exigidos para la declaración de Municipio Turístico, lo comunicarán a la Consejería en el plazo de un mes.

\subsection{Obligaciones de la Administración de la Junta de Andalucía.}

Para compensar el mayor esfuerzo financiero adicional que realiza el Municipio Turístico en la prestación de los servicios, motivado por el carácter turístico del mismo, la Administración de la Junta de Andalucía, a través de la Consejería de Turismo y Deporte y demás Consejerías que suscriban los convenios, estará obligada a considerarlo en las acciones de ordenación y fomento de sus planes económicos sectoriales, sin perjuicio de lo establecido en el Título VIII de la Ley General de la Hacienda Pública de la Comunidad Autónoma de Andalucía -art. 14 Decreto 158/2002-. Aunque no lo mencione el Decreto, debe entenderse que, entres los planes sectoriales, se encuentra precisamente el Plan General de Turismo.

\footnotetext{
${ }^{88}$ En el Decreto de Galicia 39/2001 -art. 20- se establece una periodicidad anual para este suministro de información, y que puede estimarse excesivamente espaciada.
} 
Por lo demás, el Decreto 158/2002 omite mayores precisiones en materia financiera, como podrían ser la consideración prioritaria de los MT en los programas autonómicos de cooperación territorial ${ }^{89}$, o en los planes provinciales para la cooperación a las obras y servicios municipales ${ }^{90}$.

\section{PÉRDIDA DE LA CONDICIÓN DE MUNICIPIO TURÍSTICO}

El Decreto 158/2002 -art. 17.1- establece que la declaración de Municipio Turístico tendrá carácter indefinido ${ }^{91}$ pudiendo dejarse sin efecto por alguna de las siguientes causas:

a) Pérdida de los requisitos exigidos para su declaración.

b) Variación sustancial de las circunstancias y servicios del artículo 3 del presente Decreto considerados al emitir la declaración de Municipio Turístico ${ }^{92}$.

c) Grave incumplimiento, por parte del municipio, de las obligaciones establecidas en los convenios ${ }^{93}$.

d) A petición propia del municipio, de acuerdo con el artículo $4.3 \mathrm{del}$ presente Decreto.

En los tres primeros supuestos el Delegado Provincial de Turismo y Deporte iniciará de oficio un procedimiento en el que se dará audiencia al municipio, y que se tramitará y la resolución se adoptará de acuerdo con las reglas previstas para el procedimiento de declaración de MT, lo cual significa que deberá participar el Consejo Consultivo Andaluz y la resolución deberá ser acordada por el Consejo de Gobierno. Por lo demás, la resolución habrá de ser notificada en el plazo de seis meses desde su iniciación -art. 17.2 Decreto-.

\footnotetext{
${ }^{89}$ Ley de Cataluña 13/2002 -art. 20-.

${ }^{90}$ Decreto de Galicia 39/2001 -art. 19.2-.

${ }^{91}$ En el mismo sentido, Decreto de Galicia 39/2001 -art. 21.1-.

92 De modo similar, Ley Comunidad Valenciana 3/1998 -art. 31-; Ley de Cataluña 13/2002 -art. 22.1-.

${ }^{93}$ De modo similar, Ley Comunidad Valenciana 3/1998 -art. 31-.
} 
En el cuarto supuesto ${ }^{94}$ una vez que la Delegación Provincial remita el expediente a la Dirección General de Planificación Turística y que sea comprobada su adecuación al presente Decreto, el titular de la Consejería de Turismo y Deporte adoptará la resolución por la se deje sin efecto la declaración. De este modo, no será necesaria la consulta al Consejo Consultivo Andaluz ni el acuerdo del Consejo de Gobierno ${ }^{95}$. En el supuesto de que no sea notificada la resolución en el plazo de un mes, el municipio podrá entender estimada la solicitud.

En todos estos casos, debe entenderse que la pérdida de la condición de MT supondrá la extinción sobrevenida de los convenios vigentes, por pérdida de su presupuesto de hecho, sin perjuicio de que se arbitren las medidas necesarias para su cancelación y, en su caso, puedan haberse comprometido responsabilidades por incumplimiento unilateral de los mismos.

\section{CONCLUSIÓN}

Con carácter general, puede señalarse que las expectativas económicas que suscita desde los gobiernos municipales la figura del Municipio Turístico están probablemente en el fondo de la acusada prevención con la que las Comunidades Autónomas están abordando esta institución, tanto en la decisión sobre su recepción o no, como, en su caso, en su conformación y posterior aplicación. Asimismo, el concepto mismo de MT y su configuración han evolucionado con el paso de su tratamiento desde la legislación autonómica de régimen local a la legislación turística: de un lado, la diferencia antes nítida entre MT y municipio o zona de interés turístico se ha desdibujado, al menos en parte; de otro lado, ya no se trata tanto de articular un estatuto específico para los MT, esto es un régimen local estructural de carácter especial, sino que, de un modo mucho más modesto y funcional, lo que se trata simplemente es de abrir vías a la cooperación interadministrativa preferente y bilateral.

En el caso concreto de Andalucía, debe reconocerse el ejercicio de responsabilidad por parte de las instituciones autonómicas por la recepción del MT, primero en la Ley 12/1999 y su posterior desarrollo reglamentario, con-

\footnotetext{
94 Tal como señaló el Consejo Consultivo Andaluz en su dictamen al Proyecto de Decreto, habría sido más correcto que el precepto se remitiese a la letra a) del n⿳o 1 del mismo precepto.

${ }^{95}$ De modo similar, Ley de Cataluña 13/2002 -art. 22.2-.
} 
tenido en el Decreto 158/2002, sin perjuicio de que algunos aspectos singulares de la conformación normativa puedan ser cuestionables. Básicamente, se aprecia un marcado desequilibrio entre las exigencias y condiciones rigurosas que se imponen a los Municipios para la declaración de MT, y los nulos efectos jurídicos que dicha declaración entraña por sí misma, pues la entera eficacia de la declaración se reenvía a las posteriores negociaciones bilaterales. Y, del mismo modo, se observa en el Decreto 158/2002 un salto entre la fase procedimental, adornada de la típicas garantías jurídicas, con objeto de garantizar un tratamiento no discriminatorio y leal por parte de la Administración autonómica, y la fase de negociación de los convenios, que da contenido a la declaración, y en la cual la Administración autonómica se mueve con absoluta discrecionalidad y sin estar sometida a plazo alguno. De tal modo, que cabe preguntarse de qué sirve establecer un riguroso procedimiento de concesión del título formal de MT, si después el reparto de los fondos se efectúa en negociaciones bilaterales, sin ningún tipo de condicionamiento o parámetro general.

En cualquier caso, la ordenación del MT en el ordenamiento andaluz constituye un ejemplo notorio de esa tendencia del actual Derecho Administrativo a huir de las ordenaciones generales o comunes, y no sólo adaptar o perfilar las instituciones a las circunstancias concretas, sino incluso diseñar o configurar la institución misma según las circunstancias de cada caso concreto. En efecto, la Ley 12/1999 no predetermina en absoluto los efectos de la declaración de MT, pero tampoco lo hace el Decreto 158/2002, y ni si quiera los singulares Acuerdos del Consejo de Gobierno de declaración de MT, los cuales, a su vez, deben ser desarrollados, no ya por uno sino por múltiples convenios interadministrativos. En definitiva, estamos ante el Derecho Administrativo a la Carta. 